\title{
Serum Procalcitonin Assay for Investigations and Clinical Management of Neonatal Sepsis: A Review
}

\author{
Idris Abdullahi Nasir ${ }^{1}$ Hadiza Umar Mele ${ }^{2}$ Adamu Babayo ${ }^{3}$ Fatima Yahaya ${ }^{2}$
}

${ }^{1}$ Department of Medical Microbiology, University of Abuja Teaching
Hospital, Abuja, Nigeria
2 Clinical Laboratory Unit, National Board for Technical Education,
Kaduna State, Nigeria
${ }^{3}$ Department of Medical Laboratory Sciences, University of Maiduguri,
Maiduguri, Nigeria

Address for correspondence Idris Abdullahi Nasir, BMLS (Hons.), Department of Medical Microbiology, University of Abuja Teaching Hospital, PMB 228 Gwagwalada, Abuja, Nigeria (e-mail: eedris888@yahoo.com).

J Pediatr Infect Dis 2015;10:3-11.

\begin{abstract}
Keywords

- procalcitonin

- sepsis

- biomarker

- diagnosis

- neonates
\end{abstract}

\section{Introduction}

Sepsis remains one of the most common diseases of the neonates and is still a significant cause of morbidity and mortality. ${ }^{1}$ It contributes up to 13 to $15 \%$ of all deaths during the neonatal period, higher in developing countries where it contributes between 30 and $50 \%{ }^{2,3}$ It is important to note that 20 to $30 \%$ of the survivors of neonatal sepsis (NS) may exhibit neurological sequelae. ${ }^{4}$ Sepsis-related mortality is

received

September 24, 2014

accepted after revision

November 27, 2014

however largely preventable with rational antimicrobial therapy and aggressive supportive care. ${ }^{5}$

The organisms responsible for NS vary across geographical locations and with the time of onset of illness. ${ }^{6}$ In addition, one organism or a group of organisms may over time replace another as the leading cause of NS in a particular region. ${ }^{7,8}$ In most developing countries, gram-negative bacteria remain the major source of infection. ${ }^{4}$ However, in developed countries, gram-positive bacteria are the most common causes of NS. ${ }^{9}$

Copyright @ 2015 by Georg Thieme Verlag KG, Stuttgart · New York
DOI http://dx.doi.org/ 10.1055/s-0035-1554969. ISSN 1305-7707. 
Microorganisms implicated in NS have developed increased resistance to commonly used antibiotics thus making treatment extremely difficult. ${ }^{10}$ Against this background, it is important that the etiologies and epidemiology of NS are constantly monitored locally to detect changes in the pattern of pathogens and their antibiotic susceptibilities. These data can then be used to ensure that empiric antibiotic regimens are optimized. Emerging bacterial antimicrobial resistance also calls for more stringent efforts to reduce antibiotic overuse $^{11}$; antibiotic stewardship programs aim to reduce antibiotic overuse by tailoring antibiotic therapy to the needs of individual patients. ${ }^{12,13}$

Clinical observations and/or microbiological diagnostic methods are less than $100 \%$ reliable for diagnosis of bacterial infections, and certainly have a poor negative predictive value, meaning that they are of limited value to identifying patients who do not require antibiotic therapy. The main disadvantages of many current microbiological diagnostic methods are diagnostic delays (especially with culture-based methods), suboptimal sensitivity (e.g., blood cultures), and low specificity because of contamination (e.g., sputum cultures); in addition, some sample types are not amenable to routine diagnostics because of their invasive nature (e.g., lung biopsy).

Another approach is to measure inflammatory markers, such as, C-reactive protein (CRP) or white blood cells, but these lack specificity for bacterial infections. This is partly explained by the heterogeneity of different infections and the complex interaction of different pro- and anti-inflammatory mediators of the host response aimed at combating invading pathogens during systemic infections, which depends on the time, type, extent, and site of the underlying infection. In this diagnostic dilemma, procalcitonin (PCT) has stimulated great interest as a potentially more specific marker for bacterial infection. PCT is produced ubiquitously in response to endotoxin or mediators released in response to bacterial infections (e.g., interleukin [IL]-1 $\beta$, tumor necrosis factor [TNF]- $\alpha$, and IL-6), and strongly correlates with both the presence and the severity of bacterial infection. ${ }^{14}$ Because upregulation of PCT is attenuated by interferon (INF)-g, a cytokine released in response to viral infections, PCT is more specific for bacterial infections and may help to distinguish bacterial infections from viral illnesses. ${ }^{15-17}$ PCT also has a favorable kinetic profile for use as a clinical marker: the concentration rises promptly (within 6-12 hours), and levels halve daily when the infection is controlled by the host immune system or antibiotic therapy. ${ }^{18}$ PCT correlates with bacterial load and severity of infection. ${ }^{19}$ PCT thus has potential prognostic value; the course of PCT concentrations has been found to predict fatal outcome in patients with community acquired pneumonia ${ }^{20}$ and critically ill patients with sepsis (e.g., children). ${ }^{21}$

On the basis of this evidence, PCT has been proposed as a promising candidate marker for diagnosis and for antibiotic stewardship in patients with systemic infections. ${ }^{22}$ As with any laboratory investigation, PCT measurement must be embedded in clinical algorithms, so that it is used appropriately according to the type of infection and the clinical context and setting. While for some types of infections and clinical settings, optimal PCT cutoffs have been established and their safety and efficacy shown in randomized-controlled intervention trials, for other types of infection only, observational studies are available today and thus the clinical benefit and safety of using PCT remains undefined. The aim of this review is to summarize the current evidence for PCT in sepsis in children and discuss the strengths and limitations of PCT and the reliability of this marker when used with validated diagnostic algorithms and guide for antimicrobial therapy.

\section{Biochemistry of Procalcitonin}

PCT is a 116 amino acid peptide that has an approximate molecular weight (MW) of $14.5 \mathrm{kDa}$ and belongs to the calcitonin (CT) superfamily of peptides. It can be divided into three sections including the amino terminus of the PCT region, immature $\mathrm{CT}$, and $\mathrm{CT}$ carboxyl-terminus peptide- 1 (CCP-1, also called katacalcin). PCT is encoded by the CALC-1 gene located on chromosome 11 . Cleavage in one site of the primary transcript of CALC-1 gene produces pre-PCT, which further undergoes proteolytic cleavage of its signal sequence to produce PCT. ${ }^{19,23}$

The other members of the CT superfamily of peptides include CT gene-related peptide I, II (CGRP-I and CGRP-II), amylin, and adrenomedullin. CT gene-related peptide I is also encoded by $C A L C-1$ gene and is generated by alternative splicing of the primary transcript of CALC-1 mRNA. CT gene-related peptide II, amylin, and adrenomedullin are encoded by other genes. PCT expression occurs in a tissuespecific manner. In the absence of infection, transcription of the CALC-1 gene for PCT in non-neuroendocrine tissue is suppressed, except in the $C$ cells of the thyroid gland where its expression produces PCT, the precursor of CT in healthy and noninfected individuals. The synthesized PCT then undergoes posttranslational processing to produce small peptides and mature CT, which is generated as a result of the removal of the C-terminal glycine from the immature CT by peptidylglycine $\alpha$-amidating monooxygenase.

Mature CT is stored in secretory granules and is secreted into the blood to regulate the calcium concentration. In the presence of bacterial infection, nonneuroendocrine tissues also express the CALC-1 gene to produce PCT; such an infection induces a substantial increase in CALC-1 gene expression in all parenchymal tissue and differentiated cell types in the body producing PCT. The function of PCT synthesized in the nonneuroendocrine tissues under microbial infection is presently unclear. ${ }^{19,23}$ However, PCT concentrations have been found to be a more specific marker of bacterial infection than other commonly used laboratory measures of the inflammatory response. ${ }^{23}$

\section{Pathogenesis of Sepsis}

The pathogenesis of sepsis is complex. The inflammatory cascade begins with an injury to the host, such as burns and infection. The mounted inflammatory response is meant to protect the host from tissue damage, but many inflammatory 
mediators have the potential to harm the host as well. The prevailing, although debated theory, is that sepsis occurs when the host response overwhelms the protective mechanisms in place, resulting in a superimposing injury to the patient in addition to the infection that initially triggered this response. $^{24}$

The host systemic inflammatory response is because of the following three factors: humoral, cellular, and neuroendrocrine reactions. Inflammatory cells such as neutrophils, monocytes, macrophages, basophils, and platelets interact with endothelial cells via cell mediators that further amplify the inflammatory response. Microvascular blood flow may eventually be affected by the activation of the coagulation and complement systems, resulting in local ischemia, which impairs cellular respiration. The end result is tissue hypoxia in which the systemic oxygen delivery is insufficient to meet the oxygen demands of the body. This leads to decreased myocardial contractility, decreased systemic vascular resistance, hypotension, metabolic acidosis, hyperglycemia, and ultimately, multiorgan dysfunction syndrome and death. ${ }^{24}$ The pathophysiology of sepsis therefore involves host immune, inflammatory, and coagulation responses to infection (-Fig. 1). From a clinical point of view, sepsis is currently regarded simply as an exaggerated hyperinflammatory response to infection. This inflammatory response results in release of cytokines, such as the interleukins families and TNF- $\alpha$, which in turn stimulate PCT release. ${ }^{24}$

\section{Epidemiology of Sepsis}

Bacterial sepsis is an important cause of neonatal mortality (deaths in the first 28 days of life). ${ }^{25,26}$ The World Health Organization estimated that there are approximately five million neonatal deaths per year, of which $98 \%$ occur in developing countries. ${ }^{27}$ These neonatal deaths are attributed principally to infection, birth asphyxia, and consequences of premature birth and low birth weight. It is known that risk factors for neonatal bacterial sepsis are complex and include interaction of maternal-fetal colonization, transplacental immunity, physical, and cellular defense mechanisms of the neonate. ${ }^{28}$ The incidence of neonatal bacterial sepsis varies from country to country as well as within the same country. In developing countries, neonatal mortality resulting from all causes of NS is approximately 34 per 1,000 live births, occurring mainly in the first week of life, whereas it is 5 per 1,000 live births in the developed countries. ${ }^{29}$ Neonatal mortality is approximately 34 per 1,000 live births in Asia, 42 per 1,000 live births in Africa, and 17 per 1,000 live births in Latin America and the Caribbean. ${ }^{30}$ Neonatal mortality in African countries ranges from 11 per 1,000 live births in South Africa, through 48 per 1,000 live birth in Nigeria, to 68 per 1,000 live births in Liberia.

Bacterial causes of NS differ between countries. However, in most developing countries gram-negative bacteria are the major source of infection. Increasing antibiotic resistance among the bacteria causing NS has made the management of this condition a challenge for both the public and private health sectors. ${ }^{10,31}$ Knowledge of local and regional health problems is a prerequisite for establishing an effective health care delivery system and epidemiological and statistical information regarding NS is the basis for establishing a sound program for early detection and effective treatment of infection. ${ }^{31,32}$ The etiology and epidemiology of NS and antibiotic resistance patterns of pathogens may be used to develop guidelines for management of NS in hospital including choice of diagnostic measure and empiric antibiotic therapy.

\section{Laboratory Investigations of Sepsis}

The traditional method of diagnosis for sepsis includes culturing blood, urine, cerebrospinal fluid, or bronchial fluid specimens, which usually takes 24 to 48 hours. Unfortunately,

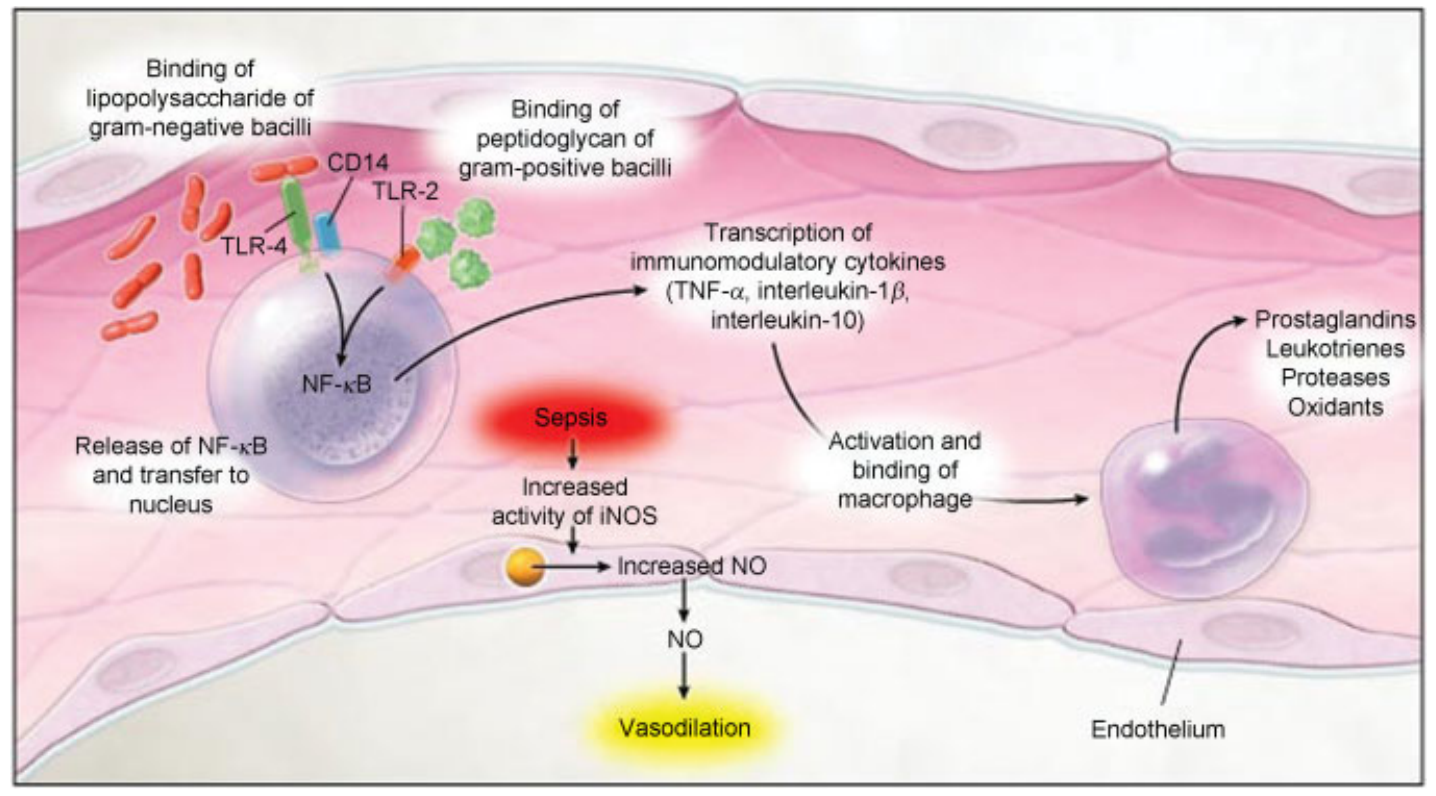

Fig. 1 Sketch diagram of immune activities during sepsis. 
clinical symptoms frequently manifest themselves in the absence of a positive culture. ${ }^{24,33}$ The traditional clinical signs of infection and routine laboratory tests, such as CRP concentration or leukocyte count, lack diagnostic accuracy and are therefore sometimes misleading. In severe infections, most classical proinflammatory cytokines, such as, TNF- $\alpha$, IL-1 $\beta$, or IL-6, are increased only briefly or intermittently, if at all. None of these tests offer a reliable means of diagnosing, or ruling out, sepsis. ${ }^{24,33}$

\section{Clinical Applications of Procalcitonin}

Several serum biomarkers have been identified in the recent years that have the potential to help diagnose local and systemic infections, differentiate bacterial and fungal infections from viral syndromes or noninfectious conditions, prognosticate, and ultimately guide management, particularly of antibiotic therapy. Among these, PCT is the most extensively studied biomarker. ${ }^{33,34}$ Numerous studies have investigated the potential roles of PCT in diagnosing and managing local and systemic infections. ${ }^{35}$ There is some evidence that PCT is more specific than other markers for bacterial infections, with serum levels rising at the onset of infection and falling rapidly as the infection resolves ${ }^{36}$; however, its clinical utility in diagnosing and managing patients with suspected infections remains inconclusive.

Clinical signs of systemic inflammation including changes in body temperature and tachycardia, and routine laboratory tests such as leukocytosis and CRP are used for diagnosis of sepsis. Because of nonspecific signs and symptoms of sepsis, the diagnosis of NS is quite difficult and can be misleading because critically ill neonates often manifest systemic inflammatory response syndrome without infection. ${ }^{35,36}$

CRP has important limitations as a marker for diagnosis of NS. Elevated CRP levels are seen in a range of conditions as well as in infection, such as autoimmune disease, surgery, meconium aspiration, and recent vaccination. Also, CRP values do not rise significantly until almost 14 to 48 hours after the onset of infection. ${ }^{37}$ Against this background, PCT has been proposed as a marker of bacterial sepsis in critically ill patients. PCT has a half-life of 25 of 30 hours. $^{38}$ The exact sites of production of PCT in sepsis have not been identified, but monocytes and hepatocytes are the most likely sources. $^{36,39}$

Bacterial lipopolysaccharide (LPS) is a potent inducer of PCT release into the systemic circulation. ${ }^{40}$ The PCT concentration starts to rise from 3 to 4 hours after an endotoxin challenge, peaks at approximately 6 hours, and remains increased for over 24 hours. ${ }^{41}$

In healthy people, PCT levels are very low. In systemic infections, including sepsis, PCT levels are generally at least 0.5 to $2 \mathrm{ng} / \mathrm{mL}$, and often reach levels of greater than $10 \mathrm{ng} / \mathrm{mL}$. Higher levels correlate with the greater severity of illness and poorer prognosis (-Fig. 2). However, in patients with respiratory tract infections, the levels of PCT are not necessarily as elevated, and a cutoff of greater than $0.1 \mathrm{ng} / \mathrm{mL}$ seems to be predictive of bacterial respiratory tract infection requiring antibiotic therapy. ${ }^{41}$ The cutoffs for other clinical

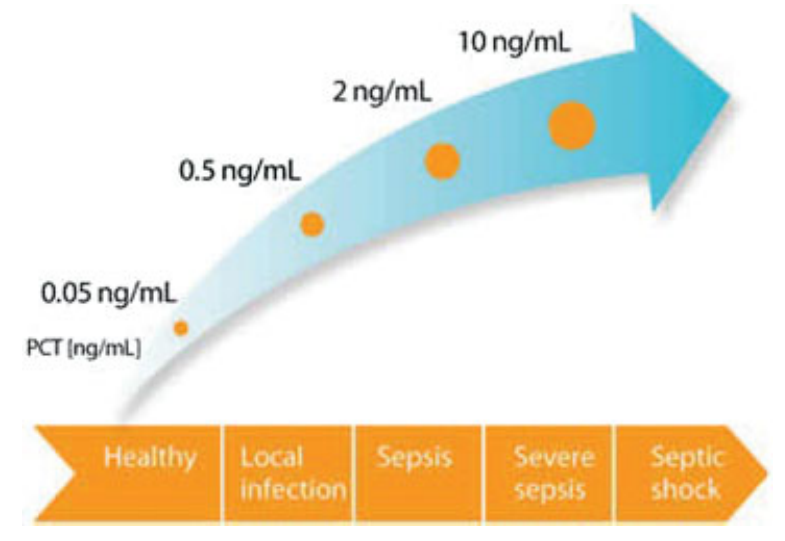

Fig. 2 Procalcitonin values rise in relation to sepsis severity.

situations may also be quite different. For example, neonates normally show a characteristic increase in PCT after birth, with a rapid return to normal by 48 to 72 hours. In neonates, a nomogram for PCT cutoffs that accounts for the time from birth in hours must be used. PCT levels may also be elevated following surgery, but there will nevertheless also be an incremental increase in patients with infection. The cutoff level of PCT to identify postoperative patients with infection may be higher than that used for nonsurgical patient groups. Although PCT may have a role in diagnosis and identification of patients who need initiation of systemic antibiotics, it may have greater applicability in guiding decisions about when to discontinue antibiotic therapy as PCT levels quickly return to less than $0.1 \mathrm{ng} / \mathrm{mL}$ as infection resolves. ${ }^{40,41}$

PCT, the precursor of the hormone CT, is known to be produced in the thyroid gland, liver, and neuroendocrine cells of the lungs and intestine. PCT is now considered to be a "hormokine," that is, it is a hormone that exhibits cytokinelike behavior of hormones during inflammation and infection, but its exact role in health and disease has not yet been established. ${ }^{42}$ In experiments, hepatic tissue stimulated by TNF- $\alpha$ or IL-6 produce PCT in significant amounts in the 24th hour after stimulation. ${ }^{43}$ PCT was first proposed as a diagnostic test for bacterial infection in 1993 by Assicot et al, who used it to differentiate bacterial from viral meningitis. Since then, many investigators have investigated PCT as a marker of bacterial infection, and it now has a widening range of potential applications, including investigation of NS. ${ }^{44}$

In hospital neonatology, bacterial infections cause significant mortality and morbidity. ${ }^{45}$ Early diagnosis of bacterial infection in neonatal resuscitation is difficult but essential, because delay in initiating of antibiotic therapy adversely affects prognosis. In the absence of reliable infection markers during the first hours of life, pediatricians often start early antibiotic treatment in newborns with risk factors for infection, exposing a considerable number of patients to unnecessary treatment. Serum PCT in cord blood seems to be a useful early marker of antenatal infection and early-onset NS. In one study, ${ }^{46}$ PCT and CRP concentrations in umbilical cord blood of 197 neonates were measured to evaluate their values as 
markers for infection. Overall, 16 of the neonates were infected. The sensitivities, specificities, and negative and positive predictive values were respectively $87.5,98.7,87.5$, and $98.7 \%$ for PCT and 50, 97, 67, and 94\% for CRP. Serum PCT in cord blood therefore seems to be a useful and early marker of antenatal infection that is more reliable than CRP. Focusing on PCT concentrations in umbilical cord blood before the physiological increase or eventual respiratory or hemodynamic failure makes interpretation for the diagnostic value of PCT concentration easier. On the contrary, the limitation of such an early PCT measurement is that it does not allow the detection of "late" maternofetal infection related to perpartum or postnatal transmission. ${ }^{46}$ The high negative predictive value of PCT measurement should result in a reduction in the number of patients receiving unnecessary antibiotics. Importantly, PCT seems to be present in full-term and preterm neonates. $^{47}$

Any reduction in antibiotic prescriptions would be a direct advantage for neonates, because of the potential toxicity for antibiotics, and an indirect ecological advantage by reducing antibiotic selection pressure. Two other important studies have reported on the potential benefits of PCT in the diagnosis of NS at 24 hours of age, and in informing the duration of antibiotic therapy. ${ }^{48}$ Stocker et $\mathrm{al}^{49}$ in a large multicenter study showed that PCT determination shortened the duration of antibiotic therapy in newborns with suspected early-onset NS.

\section{Measurement of Procalcitonin}

Different assays for measurement of PCT (PCT-I and PCT-II) are commercially available. The rights for clinical measurement of CT precursors in various indications are protected by a patent. The patent holder, BRAHMS, supplies the test kits. These include an immunoluminometric assay (ILMA; LUMItest-PCT kit, BRAHMSDiagnostica GmbH, Berlin, Germany), an assay based on timeresolved amplified cryptate emission technology (Kryptor PCT, BRAHMS-Diagnostica GmbH, Berlin, Germany), and a semiquantitative rapid test (BRAHMS PCT-Q BRAHMS-Diagnostica $\mathrm{GmbH}$, Berlin, Germany). These assays are available as semiautomated manual systems and fully automated stat systems. The test results are available within times ranging from 19 minutes (Kryptor PCT), through 30 minutes (rapid test BRAHMS PCT-Q), to 1 hour (LUMItest PCT).

The analytical sensitivity of the quantitative test methods ranges between $0.06 \mathrm{ng} / \mathrm{mL}$ (Kryptor PCT) and $0.1 \mathrm{ng} / \mathrm{mL}$ (LUMItest PCT), the functional assay sensitivity (20\% interassay variation coefficient) is approximately $0.3 \mathrm{ng} / \mathrm{mL}$ (ILMA), and somewhat less for the Kryptor technology. The LUMItest PCT utilizes two mouse monoclonal antibodies against human CT and katacalcin. Kryptor PCT is based on a sheep polyclonal anticalcitonin antibody and a monoclonal antikatacalcin antibody, which bind either to the katacalcin and the CT sequence of CT precursor molecules. Accordingly, neither the N-terminal amino acids of the molecule (aminoprocalcitonin or "N-pro") nor the different "amino acids" distinguishing PCT-I and PCT-II are required for antibody binding. These commercially available assays measure
PCT-I, PCT-II, and various cleavage products of CT precursor molecules consisting at least of the residues of $\mathrm{CT}$ and katacalcin. For research purposes, concentrations of the various cleavage products of CT precursor molecules can be measured by HPLC ${ }^{43-45}$ or by individually designed antibody systems, for example, radioimmunoassay. ${ }^{50}$

Compared with the results obtained using the commercially available kits, the research-related technologies may yield different concentration measurement results for the different CT precursor molecules and depending on the biochemical properties of each cleavage product-to different normal and pathological ranges for these proteins. Differences in the induction and elimination kinetics may also play a role. However, almost every clinical study described in the literature so far has been conducted using the commercially available, patented antibody systems. Therefore, the related CT precursor concentration measurements, usually summarized as "PCT," can be considered to be comparable among the various studies. ${ }^{23,50}$ Samples suitable for the assay can be serum or plasma using either EDTA or heparin as the anticoagulants but not citrate as this has been shown to underestimate PCT levels. ${ }^{51}$

\section{Limitation of Procalcitonin Assays and Areas of Uncertainty}

Sepsis is not a well-defined disease, but a consequence of different infectious disease entities and far too complex to be reduced to a single cutoff of any surrogate marker. Limitations of every PCT measurement include false-positive and falsenegative results. ${ }^{52,53}$ Different pathogens might induce distinct responses resulting in a variable upregulation of circulating PCT levels. ${ }^{54}$

While highly elevated PCT levels were found in patients with pneumococcal community-acquired pneumonia, the same was not true in community acquires pneumonia because of the atypical organisms such as mycoplasma. ${ }^{54}$ Antimicrobial pretreatment may influence the level of PCT resulting in lower PCT levels, ${ }^{54}$ although it remains unclear whether this relates to a direct effect or rather to lower microbial burden in patients treated with antibiotics. Nonspecific elevations of PCT levels in the absence of a bacterial infection can be seen in situations of massive stress, for example, after severe trauma and surgery, ${ }^{55,56}$ or in patients after cardiac shock. ${ }^{57}$ Although the available evidence from intervention studies favors the use of PCT for escalation of antibiotic therapy, this does not necessarily improve survival, and may even result in harm and prolonged intensive care unit admission. ${ }^{58}$

There are also reports in the literature where elevations in PCT levels were not connected with bacterial infections, for example, in an Addisonian crisis, ${ }^{59}$ or in transplant patients receiving pan $T$ cell antibody therapy. ${ }^{60}$ Recently, Brodska et al reported marked elevations in PCT and CRP levels in patients scheduled for hematopoietic stem cell transplantation and receiving antithymocyte globulin during conditioning. ${ }^{61}$ In malaria, PCT levels are elevated in both severe and uncomplicated Plasmodium falciparum malaria but could not be used to differentiate between the two types and was thus of limited use in its diagnosis. ${ }^{55,61}$ 
PCT has been found to have little value in the diagnosis of pulmonary tuberculosis (PTB). ${ }^{62}$ Baylan et al found that serum PCT levels were slightly higher on admission in patients with active PTB in comparison with controls and patients on antituberculous chemotherapy. However, although this difference was statistically significant, the PCT levels in most cases of PTB were not elevated (58.7\%). ${ }^{63}$

\section{Prognostic Implications of Serum Procalcitonin}

PCT concentration is closely related to the severity of systemic inflammation, and the kinetics of PCT induction and elimination are reliably predictable. ${ }^{23,64}$ Serial PCT measurement can, therefore, be used to monitor disease activity in patients with sepsis and systemic inflammation. These measurements can serve as an aid in therapeutic and diagnostic decision making, as a decline or increase in PCT indicates changes in the activity of systemic inflammation that may or may not require modification of the diagnosis or therapy. The course of PCT concentrations over time is also related to the prognosis of systemic inflammation. Continuously increasing plasma PCT levels usually indicate that the systemic inflammation has not subsided, the infection is not under control and/or the therapeutic measures are not effective. These patients are more likely to have a poorer prognosis. ${ }^{23,64}$ Initially, high PCT concentrations do not necessarily indicate a poor prognosis, especially when the inflammation or underlying disease responds well to treatment. ${ }^{64}$

\section{Principles of Procalcitonin Interpretation}

1. Interpret in the clinical context of the patient. For example, patients with septic shock neonates should not have antibiotics withheld based on normal PCT. Patients with mild elevations in PCT who exhibit no signs or symptoms of infection may be closely monitored.

2. Serial measurements are preferred and provide more useful information. For example, patients very early in the onset of infection may have a normal PCT value. Patients who have persistently normal PCT levels are unlikely to have bacterial infection. Patients with other inflammatory events such as major surgery who have steadily decreasing PCT levels often do not need antibiotics.

3. Consider the dynamics of the disease. For example, patients with severe trauma without infection should have PCT levels which steadily decline. Also, patients with severe infections (bacteremic pneumonia) will generally take longer for PCT levels to normalize.

4. Be aware of conditions which may affect PCT levels. For example, a patient with peritonitis who returns to the OR for a washout is expected to have a transitory increase in PCT value postoperatively.

\section{Costs}

Physicians should consider the increased cost associated with the use of additional tests. PCT cost is approximately twice that of CRP, but provides greater clinical value in the overall management of the patient, especially when used for determination of cessation of antibiotics. A cost benefit analysis of PCT use in the ICU found cost savings or increased cost of care depending on how frequently PCT was utilized and the cost of the antibiotics which were discontinued. ${ }^{65}$

\section{Procalcitonin as a Guide for Antibiotic Decisions}

The clinical implications of some observational studies may be limited by differences in disease definitions and patient groups, use of insensitive (semiquantitative) PCT assays, and different methodological issues such as observer bias, selection bias and issues of sample availability, coinfection, and colonization. ${ }^{66}$ To overcome these limitations, several randomized-controlled studies have investigated the use of PCT to assist in decisions about initiation and/or duration of antibiotic therapy (antibiotic stewardship).

Importantly, all intervention studies used fully automated highly sensitive PCT assays, the results of which can be obtained in the clinical routine of an emergency department within 1 hour thus permitting bedside decision making. Recently, different options for PCT testing have become available, including the KRYPTOR, ${ }^{67}$ the VIDAS system (bioMérieux, New Delhi, India), the Liaison BRAHMS PCT (DiaSorin, Saluggia, Italy) ${ }^{68}$ and the Elecsys BRAHMS PCT (Roche Diagnostics, Indianapolis, United States). ${ }^{69}$

All published studies on antibiotic stewardship used similar clinical algorithms with recommendations for or against antibiotic treatment based on PCT cutoff ranges. ${ }^{70}$ For moderate risk patients with respiratory tract infections in the emergency department, algorithms recommended initiation and discontinuation of antibiotic therapy based on four different cutoff ranges. Initial antibiotics were withheld mostly in patients with low risk for systemic infection with acute bronchitis or exacerbation of chronic obstructive pulmonary disease (ECOPD). Clinical reevaluation and a repeated measurement of PCT were recommended after 6 to 24 hours if the clinical condition did not improve spontaneously. If PCT values were increased and antibiotic therapy was initiated, repeated PCT measurements were recommended every 1 to 2 days, depending on the clinical severity of disease, and antibiotics were discontinued using the same cutoff ranges or a marked drop by 80 to $90 \%$ if initial levels were high (e.g., $>5$ $\mathrm{ng} / \mathrm{mL}$ ). To assure safety, specific criteria were predefined where this algorithm could be overruled, such as, life-threatening disease or immediate need for ICU admission. For highrisk patients in the ICU setting and SCBU, algorithms focused on discontinuation of antibiotic therapy if a patient showed a clinical recovery and PCT levels decreased to "normal" levels, or by at least 80 to $90 \%{ }^{70}$

The first intervention study testing PCT as a guide for antibiotic decisions included patients with different types and severities of respiratory infections. Clinical outcomes for both groups were similar, but the PCT-guided group had markedly lower rates of antibiotic prescriptions (44 vs. 83\%), particularly in patients with ECOPD and acute bronchitis. Two 
subsequent trials evaluated the effect of PCT guidance for antibiotic discontinuation in CAP and ECOPD. PCT guidance reduced the duration of antibiotic therapy by $65 \%$ in patients with CAP and the prescription of antibiotics from 72 to $40 \%$ in patients with ECOPD. ${ }^{71}$

In high-risk patients in the ICU setting, different trials have investigated the use of PCT, mainly for discontinuation of antibiotics. The first small proof of concept study Nobre et al found a 4-day reduction in the duration of antibiotic therapy in patients with severe sepsis, but only in the per protocol analysis. ${ }^{72}$ A subsequent large multicenter trial in France recently validated this concept in more than 600 patients. $^{72}$ PCT-guided patients had similar 30-day mortality rates and similar rates of relapses, but markedly more antibiotic-free days alive (14.3 vs. 11.6). Another multinational ICU study focused on ventilator-associated pneumonia and found that PCT guidance resulted in a higher number of antibiotic freedays alive (13 vs. 9.5 days). ${ }^{71,72}$

Two German studies assessed the effect of PCT guidance in surgical ICU patients with suspected bacterial infections in the postoperative course. ${ }^{73,74}$ PCT guidance resulted in a significant reduction of antibiotic therapy and similar medical outcomes. In addition, the length of intensive care treatment in the PCT-guided group was significantly shorter than that in the control group (15.5 vs. 17.7 days), a finding similar to the first ICU study. Importantly, the use of PCT for discontinuation of antibiotics in ICU patients (especially neonates) is still limited by a relatively small number of patients included in previous trials and awaits further large-scale validation.

There are currently different ongoing trials focusing on this vulnerable patient population that should further shed light on the benefits and harms of PCT use in neonates. Daily PCT measurement is used, in addition to clinical judgment, to assess prognosis, to predict unfavorable outcome, and to customize the length of antibiotic therapy if necessary, as previously published. ${ }^{72-74}$ In a work by Nnanna et al at Benin, Nigeria, septicemia was clinically suspected in 60 neonates and total of 55 (91.6\%) neonates showed a positive PCT test, which proved the presence of bacterial Septicemia. ${ }^{75}$ In one Iranian study, Adib et al found $75 \%$ sensitivity, $80 \%$ specificity, $80 \%$ positive predictive value, and $75 \%$ negative predictive value for PCT as a marker for the early diagnosis of NS. ${ }^{76}$ Another Iranian study by Khoshdel et $\mathrm{al}^{77}$ in Iran showed that the sensitivity, specificity, and positive and negative predictive values of PCT measurement for NS were 87.5, 87.4, 30.4, and $99.1 \%$ respectively. Also from Iran, Zahedpasha et $\mathrm{al}^{78}$ showed that PCT levels were remarkably high in neonates with proven sepsis and dropped dramatically after antibiotic treatment.

Emerging bacterial resistance to antimicrobial therapeutics calls for more stringent efforts to reduce antibiotic overuse. One good-quality study by Stocker et al $(n=121)$ provided moderate evidence that PCT guidance reduces the use of antibiotic therapy for suspected early NS. The duration of antibiotic use was overall reduced by 22.4 hours (22.0\%). Furthermore, the proportion of neonates on antibiotics for longer than 72 hours was reduced by $27 \%$. The greatest reductions were seen among neonates who were judged according to clinical criteria to have possible infection or unlikely to have infection as compared with those with proven or probable infection. The strength of evidence was judged insufficient to make conclusions on mortality and morbidity because of the small study size.

\section{Conclusion}

In clinically significant bacterial infections, PCT is produced through an alternative pathway in all parenchymal tissues, and is excreted into the blood stream. This pathway is blocked in viral infections, making PCT a very specific marker for bacterial infections.

Once the infection is under control, for example, after antibiotic therapy, PCT production ceases and PCT values decrease by 30 to $50 \%$ from day to day, indicating that the infection is under control and the patient recovering.

With the availability of sensitive PCT measurements, it is possible to detect slightly raised PCT values in NS early and to thus differentiate between bacterial, nonbacterial inflammation, and viral infections. As the majority of respiratory tract infections are of viral origin, it is possible to reduce with the help of PCT the amount of antibiotic prescriptions. There are ample biomedical findings in support of using PCT for investigating NS and antibiotic-guided therapy. In the long run, PCT has the potential to reduce the emergence and spread of antibiotic resistance. It is also worthy to note that diagnosis of sepsis cannot be made or excluded based on single marker even PCT. There is a need to extensively evaluate and possibly consider serum PCT as an adjunctive marker to be combined to other commonly used approaches such as blood culture, full blood count, and differentials to enhance prompt and rational clinical management before blood culture results become available.

\section{Competing Interest}

The authors declare no competing interest associated with this article.

\section{Acknowledgments}

We acknowledge Dr. Yunusa Thairu, Mr. Bakare Mustapha, and Pharmacist Ibrahim Abdulkadir of University of Abuja teaching hospital for their technical advice and typesetting the final article.

\section{References}

1 Chacko B, Sohi I. Early onset neonatal sepsis. Indian J Pediatr 2005; 72(1):23-26

2 Antia-Obong OE, Utsalo SJ, Udo JJ, Udo KT. Neonatal septicaemia in Calabar, Nigeria. Cent Afr J Med 1992;38(4):161-165

3 Omene JA. Neonatal septicaemia in Benin City, Nigeria. A review of 74 cases. Trop Geogr Med 1979;31(1):35-39

4 Klein JO, Marcy MS. Bacterial Sepsis and Meningitis. In Infectious Diseases of the Fetus and the Newborn. Edited by Remington JJ, Klein JO. Philadelphia: WB Sauders Co; 1995:835-890 
5 Sankar MJ, Agarwal R, Deorari AK, Paul VK. Sepsis in the newborn. Indian J Pediatr 2008;75(3):261-266

6 Al-Zwaini EJ. Neonatal septicaemia in the neonatal care unit, AlAnbar governorate, Iraq. East Mediterr Health J 2002;8(4-5): 509-514

7 Amiebenomo CS, Yakubu AM, Bello CSS, Ewa B. Neonatal Septicaemia in Zaria. Niger Med J 1988;18:349-351

8 Edwards MS. Postnatal Bacterial Infections. In Neonatal Perinatal Medicine: Diseasesm of the Fetus and Infants. 7th edition. Edited by Fanaroff AA, Martin RJ. St Louis, MO: CV Mosby; 2002:706-726

9 Placzek MM, Whitelaw A. Early and late neonatal septicaemia. Arch Dis Child 1983;58(9):728-731

10 Motara F, Ballot DE, Perovic O. Epidemiology of neonatal sepsis at Johannesburg Hospital. Southern Afr. J Epidemiol Infect 2005; 20(3):90-93

11 Whitney CG, Farley MM, Hadler J, et al; Active Bacterial Core Surveillance Program of the Emerging Infections Program Network. Increasing prevalence of multidrug-resistant Streptococcus pneumoniae in the United States. N Engl J Med 2000;343(26): 1917-1924

12 Roberts RR, Hota B, Ahmad I, et al. Hospital and societal costs of antimicrobial-resistant infections in a Chicago teaching hospital: implications for antibiotic stewardship. Clin Infect Dis 2009;49(8): 1175-1184

13 Ohl CA, Luther VP. Antimicrobial stewardship for inpatient facilities. J Hosp Med 2011;6(Suppl 1):S4-S15

14 Gogos CA, Drosou E, Bassaris HP, Skoutelis A. Pro- versus antiinflammatory cytokine profile in patients with severe sepsis: a marker for prognosis and future therapeutic options. J Infect Dis 2000;181(1):176-180

15 Christ-Crain M, Müller B. Biomarkers in respiratory tract infections: diagnostic guides to antibiotic prescription, prognostic markers and mediators. Eur Respir J 2007;30(3):556-573

16 Christ-Crain M, Müller B. Procalcitonin in bacterial infectionshype, hope, more or less? Swiss Med Wkly 2005;135(31-32): 451-460

17 Linscheid P, Seboek D, Zulewski H, Keller U, Müller B. Autocrine/ paracrine role of inflammation-mediated calcitonin gene-related peptide and adrenomedullin expression in human adipose tissue. Endocrinology 2005;146(6):2699-2708

18 Becker KL, Nylén ES, White JC, Müller B, Snider RH Jr. Clinical review 167: Procalcitonin and the calcitonin gene family of peptides in inflammation, infection, and sepsis: a journey from calcitonin back to its precursors. J Clin Endocrinol Metab 2004; 89(4):1512-1525

19 Schuetz P, Mueller B, Trampuz A. Serum procalcitonin for discrimination of blood contamination from bloodstream infection due to coagulase-negative staphylococci. Infection 2007;35(5):352-355

20 Schuetz P, Suter-Widmer I, Chaudri A, Christ-Crain M, Zimmerli W, Mueller B; Procalcitonin-Guided Antibiotic Therapy and Hospitalisation in Patients with Lower Respiratory Tract Infections (ProHOSP) Study Group. Prognostic value of procalcitonin in community-acquired pneumonia. Eur Respir J 2011;37(2): 384-392

21 Jensen JU, Heslet L, Jensen TH, Espersen K, Steffensen P, Tvede M. Procalcitonin increase in early identification of critically ill patients at high risk of mortality. Crit Care Med 2006;34(10): 2596-2602

22 Schuetz P, Albrich W, Christ-Crain M, Chastre J, Mueller B. Procalcitonin for guidance of antibiotic therapy. Expert Rev Anti Infect Ther 2010;8(5):575-587

23 Meisner M. Pathobiochemistry and clinical use of procalcitonin. Clin Chim Acta 2002;323(1-2):17-29

24 Ming J, Adil IK. Procalcitonin: uses in the clinical laboratory for the diagnosis of sepsis. LabMedcine 2010;41:173-177

25 The WHO Young Infants Study Group. Serious infections in young infants in developing countries: rationale for a multicenter study. Pediatr Infect Dis J 1999;18(10, Suppl):S4-S7
26 Dawodu A, Twum-Danso K, Al Umran K. A case control study of neonatal sepsis: experience from Saudi Arabia. J Trop paed 1997; 43:84-88

27 World Health Organization. Perinatal mortality. Report No: WHO/ FRH/MSM/967. Geneva: WHO; 1996

28 Jumah DS, Hassan MK. Predictors of mortality outcome in neonatal sepsis. Med J Basrah Univ 2007;25:11-18

29 Costello A, Francis V, Byrne A. The state of the world's newborns. Washington: Save the Children Fund; 2001;411:1929-1934

30 Vergnano S, Sharland M, Kazembe P, Mwansambo C, Heath PT. Neonatal sepsis: an international perspective. Arch Dis Child Fetal Neonatal Ed 2005;90(3):F220-F224

31 Ako-Nai AK, Adejuyigbe EA, Ajayi FM, Onipede AO. The bacteriology of neonatal septicaemia in Ile-Ife, Nigeria. J Trop Pediatr 1999; 45(3):146-151

32 Anah MU, Udo JJ, Ochigbo SO, Abia-Bassey LN. Neonatal septicaemia in Calabar, Nigeria. Trop Doct 2008;38(2):126-128

33 Marshall JC, Reinhart K; International Sepsis Forum. Biomarkers of sepsis. Crit Care Med 2009;37(7):2290-2298

34 Tang H, Huang T, Jing J, Shen H, Cui W. Effect of procalcitoninguided treatment in patients with infections: a systematic review and meta-analysis. Infection 2009;37(6):497-507

35 Jones AE, Fiechtl JF, Brown MD, Ballew JJ, Kline JA. Procalcitonin test in the diagnosis of bacteremia: a meta-analysis. Ann Emerg Med 2007;50(1):34-41

36 Dandona P, Nix D, Wilson MF, et al. Procalcitonin increase after endotoxin injection in normal subjects. J Clin Endocrinol Metab 1994;79(6):1605-1608

37 Becker KL, Snider R, Nylen ES. Procalcitonin in sepsis and systemic inflammation: a harmful biomarker and a therapeutic target. $\mathrm{Br}$ J Pharmacol 2010;159(2):253-264

38 Summary of B.R.A.H.M.S PCT sensitive KRYPTOR® Test System. Available at: www.accessdata.fda.gov/cdrh_docs/pdf7/K070310. pdf. Accessed September 18, 2014

39 Schneider HG, Lam QT. Procalcitonin for the clinical laboratory: a review. Pathology 2007;39(4):383-390

40 Bone RC, Balk RA, Cerra FB, et al; The ACCP/SCCM Consensus Conference Committee. American College of Chest Physicians/ Society of Critical Care Medicine. Definitions for sepsis and organ failure and guidelines for the use of innovative therapies in sepsis. Chest 1992;101(6):1644-1655

41 Summary of VIDAS B.R.A.H.M.S PCT Assay. Available at: www. accessdata.fda.gov/cdrh_docs/pdf7/K071146.pdf. Accessed September 18, 2014

42 Müller B, Becker KL. Procalcitonin: how a hormone became a marker and mediator of sepsis. Swiss Med Wkly 2001;131(41-42): 595-602

43 Monneret G, Pachot A, Laroche B, Picollet J, Bienvenu J. Procalcitonin and calcitonin gene-related peptide decrease LPS-induced tnf production by human circulating blood cells. Cytokine 2000; 12(6):762-764

44 Stocker M, Fontana M, El Helou S, Wegscheider K, Berger TM. Use of procalcitonin-guided decision-making to shorten antibiotic therapy in suspected neonatal early-onset sepsis: prospective randomized intervention trial. Neonatology 2010;97(2): 165-174

45 Raimondi F, Ferrara T, Maffucci R, et al. Neonatal sepsis: a difficult diagnostic challenge. Clin Biochem 2011;44(7):463-464

46 Joram N, Boscher C, Denizot S, et al. Umbilical cord blood procalcitonin and $\mathrm{C}$ reactive protein concentrations as markers for early diagnosis of very early onset neonatal infection. Arch Dis Child Fetal Neonatal Ed 2006;91(1):F65-F66

47 Savagner C, Leboucher B, Gascoin-Lachambre G, Gras-Leguen C. Relevance of procalcitonin for the diagnosis of early and late-onset sepsis in newborns. In: Luciano Azevedo ed. Sepsis - An Ongoing and Significant Challenge. InTech; 2012:250-258

48 Altunhan H, Annagür A, Örs R, Mehmetoğlu I. Procalcitonin measurement at 24 hours of age may be helpful in the prompt 
diagnosis of early-onset neonatal sepsis. Int J Infect Dis 2011; 15(12):e854-e858

49 Stocker M, Hop WC, van Rossum AM. Neonatal Procalcitonin Intervention Study (NeoPInS): Effect of Procalcitonin-guided decision making on duration of antibiotic therapy in suspected neonatal early-onset sepsis: A multi-centre randomized superiority and non-inferiority Intervention Study. BMC Pediatr 2010; 10:89

50 Whang KT, Vath SD, Becker KL, et al. Procalcitonin and proinflammatory cytokine interactions in sepsis. Shock 2000;14(1): 73-78

51 Summary of Safety and Effectiveness. B.R.A.H.M.S PCT LIA. Available at: www.accessdata.fda.gov/cdrh_docs/pdf4/K040887.pdf. Accessed September 18, 2014

52 Christ-Crain M, Stolz D, Bingisser R, et al. Procalcitonin guidance of antibiotic therapy in community-acquired pneumonia: a randomized trial. Am J Respir Crit Care Med 2006;174(1):84-93

53 Schuetz P, Christ-Crain M, Müller B. Procalcitonin and other biomarkers to improve assessment and antibiotic stewardship in infections-hope for hype? Swiss Med Wkly 2009;139(23-24): 318-326

54 Krüger S, Ewig S, Papassotiriou J, et al; CAPNETZ Study Group. Inflammatory parameters predict etiologic patterns but do not allow for individual prediction of etiology in patients with CAP: results from the German competence network CAPNETZ. Respir Res 2009;10:65

55 Uzzan B, Cohen R, Nicolas P, Cucherat M, Perret GY. Procalcitonin as a diagnostic test for sepsis in critically ill adults and after surgery or trauma: a systematic review and meta-analysis. Crit Care Med 2006;34(7):1996-2003

56 Sponholz C, Sakr Y, Reinhart K, Brunkhorst F. Diagnostic value and prognostic implications of serum procalcitonin after cardiac surgery: a systematic review of the literature. Crit Care 2006;10(5): R145

57 Schuetz P, Affolter B, Hunziker S, et al. Serum procalcitonin, Creactive protein and white blood cell levels following hypothermia after cardiac arrest: a retrospective cohort study. Eur J Clin Invest 2010;40(4):376-381

58 Jensen JU, Hein L, Lundgren B, et al; Procalcitonin and Survival Study (PASS) Group. Procalcitonin-guided interventions against infections to increase early appropriate antibiotics and improve survival in the intensive care unit: a randomized trial. Crit Care Med 2011;39(9):2048-2058

59 Schumm J, Pfeifer R, Ferrari M, Kuethe F, Figulla HR. An unusual case of progressive shock and highly elevated procalcitonin level. Am J Crit Care 2010;19(1):96-3

60 Sabat R, Höflich C, Döcke WD, et al. Massive elevation of procalcitonin plasma levels in the absence of infection in kidney transplant patients treated with pan-T-cell antibodies. Intensive Care Med 2001;27(6):987-991

61 Brodska H, Drabek T, Malickova K, et al. Marked increase of procalcitonin after the administration of anti-thymocyte globulin in patients before hematopoietic stem cell transplantation does not indicate sepsis: a prospective study. Crit Care 2009;13(2): R37

62 Caruhel P, Mazier C, Kunde J, Morgenthaler NG, Darbouret B. Homogeneous time-resolved fluoroimmunoassay for the measurement of midregional proadrenomedullin in plasma on the fully automated system B.R.A.H.M.S KRYPTOR. Clin Biochem 2009; 42(7-8):725-728

63 Baylan O, Balkan A, Inal A, et al. The predictive value of serum procalcitonin levels in adult patients with active pulmonary tuberculosis. Jpn J Infect Dis 2006;59(3):164-167

64 Rau B, Steinbach G, Gansauge F, Mayer JM, Grünert A, Beger HG. The potential role of procalcitonin and interleukin 8 in the prediction of infected necrosis in acute pancreatitis. Gut 1997; 41(6):832-840

65 Heyland DK, Johnson AP, Reynolds SC, Muscedere J. Procalcitonin for reduced antibiotic exposure in the critical care setting: a systematic review and an economic evaluation. Crit Care Med 2011;39(7):1792-1799

66 Schuetz P, Christ-Crain M, Albrich W, Zimmerli W, Mueller B; ProHOSP Study Group. Guidance of antibiotic therapy with procalcitonin in lower respiratory tract infections: insights into the ProHOSP study. Virulence 2010;1(2):88-92

67 Steinbach G, Rau B, Debard AL, et al. Multicenter evaluation of a new immunoassay for procalcitonin measurement on the Kryptor System. Clin Chem Lab Med 2004;42(4):440-449

68 Hubl W, Krassler J, Zingler C, et al. Evaluation of a fully automated procalcitonin chemiluminescence immunoassay. Clin Lab 2003; 49(7-8):319-327

69 de Wolf HK, Gunnewiek JK, Berk Y, van den Ouweland J, de Metz M. Comparison of a new procalcitonin assay from roche with the established method on the brahms kryptor. Clin Chem 2009;55(5): 1043-1044

70 Schuetz P, Christ-Crain M, Huber AR, Müller B. Long-term stability of procalcitonin in frozen samples and comparison of Kryptor and VIDAS automated immunoassays. Clin Biochem 2010;43(3): 341-344

71 Stolz D, Smyrnios N, Eggimann P, et al. Procalcitonin for reduced antibiotic exposure in ventilator-associated pneumonia: a randomised study. Eur Respir J 2009;34(6):1364-1375

72 Nobre V, Harbarth S, Graf JD, Rohner P, Pugin J. Use of procalcitonin to shorten antibiotic treatment duration in septic patients: a randomized trial. Am J Respir Crit Care Med 2008;177(5):498-505

73 Hochreiter M, Köhler T, Schweiger AM, et al. Procalcitonin to guide duration of antibiotic therapy in intensive care patients: a randomized prospective controlled trial. Crit Care 2009;13(3):R83

74 Schroeder S, Hochreiter M, Koehler T, et al. Procalcitonin (PCT)guided algorithm reduces length of antibiotic treatment in surgical intensive care patients with severe sepsis: results of a prospective randomized study. Langenbecks Arch Surg 2009;394(2): 221-226

75 Nnanna II, Ehis OJ, Sidiquo II, Nnanna IG, Adekunle O. Serum procalcitonin: Early detection of neonatal bacteremia and septicemia in a tertiary healthcare facility. N Am J Med Sci 2011;3(3): 157-160

76 Adib M, Bakhshiani Z, Navaei F, Saheb Fosoul F, Fouladi S, Kazemzadeh H. Procalcitonin: a reliable marker for the diagnosis of neonatal sepsis. Iran J Basic Med Sci 2012;15(2):777-782

77 Khoshdel A, Mahmoudzadeh M, Kheiri S, et al. Sensitivity and specificity of procalcitonin in diagnosis of neonatal sepsis. Iranian J Pathol 2008;3:203-207

78 Zahedpasha Y, Ahmadpour KM, Hajiahmadi M, Haghshenas M. Procalcitonin as a marker of neonatal sepsis. Iran J Pediatr 2009; 19:117-122 